\title{
AS FONTES DA ESCOLA E A PESQUISA EM HISTÓRIA DA EDUCAÇÃO: CONTRIBUIÇÕES DO ACERVO DO COLÉGIO ESTADUAL DO PARANÁ PARA O CAMPO DAS DISCIPLINAS ESCOLARES
}

\author{
Serlei M. Fischer Ranzi \\ UFPR \\ serleif@gmail.com \\ Nadia G. Gonçalves \\ UFPR \\ nadiagg@ufpr.br
}

\section{RESUMO:}

Neste trabalho são discutidas duas questões centrais: o processo de organização e transformação do Arquivo do CEP em um lugar de guarda e preservação de fontes relevantes para pesquisas em História da Educação; e a análise de três pesquisas realizadas, a partir de fontes identificadas nessa instituição escolar, no campo das disciplinas escolares: Educação Física, Canto Orfeônico e História. O caminho percorrido pelos autores aqui analisados - Chaves Jr. (2004), Lemos Jr. (2005) e Kawka Martins (2006) foi de seguir a orientação de Nóvoa (1996) sobre um olhar mais atento à internalidade do trabalho escolar. Eles examinaram a instituição como um lugar privilegiado na produção das disciplinas escolares e identificaram nela aspectos comuns na compreensão e implantação de políticas públicas de educação, e algumas singularidades em função de soluções e/ou problemas específicos no local.

Palavras-chave: História das disciplinas escolares. Arquivo histórico escolar. Colégio Estadual do Paraná.

\section{THE SOURCES OF THE SCHOOL AND RESEARCH INTO THE HISTORY OF EDUCATION: CONTRIBUTIONS FROM THE COLLECTION OF THE PARANÁ STATE HIGH SCHOOL TO THE FIELD OF SCHOOL DISCIPLINES}

\begin{abstract}
:
This paper discusses two central questions: the organization and transformation process of the Archives of the Paraná State High School into a place to safeguard and preserve sources concerning studies of the History of Education; and the analysis of three studies conducted from sources identified in this learning institution in the field of school disciplines. Physical Education, Choir Singing and History. The trajectory of the authors analyzed herein Chaves Jr. (2004), Lemos Jr. (2005) and Kawka Martins (2006) followed the guidelines of Nóvoa (1996) concerning a more attentive look at the internality of school work. They examined the institution as a privileged place in the production of school disciplines and learned aspects common to the comprehension and implantation of public education policies and some singularities due to specific solutions and/or problems of the local environment.

Keywords: history of school disciplines. Historical school archive. Paraná State High school.
\end{abstract}




\section{Introdução}

O presente trabalho visa apresentar e discutir duas questões centrais: 1) a potencial contribuição do acervo documental do Colégio Estadual do Paraná - CEP, para pesquisas em História da Educação, considerando-se um projeto em desenvolvimento de organização do referido acervo; e 2) uma análise de resultados já concretizados de pesquisas realizadas, a partir de fontes identificadas nesta instituição escolar, no campo das disciplinas escolares.

O Colégio Estadual do Paraná sintetiza uma trajetória que, de certa forma, implicou em formatos e propósitos diversos, em consonância com projetos e políticas educacionais mais amplos, no país, mesmo anteriores à Primeira República, pois essa instituição foi oficialmente criada em 1846, sob a denominação Licêo de Coritiba e, posteriormente, passou a Instituto Paranaense (1876), Gymnasio Paranaense (1892), Colégio Paranaense (1942) e Colégio Estadual do Paraná (1943); também, possui porte e infra-estrutura privilegiados, além de um Museu e de um espaço físico que permitiu a guarda e preservação de significativo acervo documental.

Por outro lado, em 2008, a Linha de História e Historiografia da Educação (LHHE), do PPGE-UFPR, completou 10 anos, oportunizando a realização de alguns balanços sobre sua trajetória e produção. Esta Linha representa um locus de produção em História da Educação. No Paraná, há outros programas de Educação e de História que também contribuem com essa produção, já analisada na obra Uma cartografia da pesquisa em História da Educação na região Sul (BASTOS, BENCOSTA e CUNHA, 2004), que abrange até o ano 2000. Nela, a contribuição da LHHE estava ainda em uma fase embrionária. Sua atuação, no entanto, não se restringe à produção de pesquisas, se estende ao campo da teoria, da identificação de acervos e na preservação de fontes documentais.

No caso específico deste trabalho, serão abordadas três pesquisas realizadas no campo da História das disciplinas escolares a partir de fontes do acervo do Colégio Estadual do Paraná: Educação Física (CHAVES JR., 2004), Canto Orfeônico (LEMOS JR., 2005) e História (KAWKA MARTINS, 2006). O recorte e a escolha desses trabalhos sobre a História das disciplinas escolares se devem, em primeiro lugar, porque possuem uma problemática comum e um recorte temporal bastante aproximado e, também, porque possibilitam algumas generalizações sobre a escola secundária, no período de 1930 a 1950. Além disso, os autores partem da escola, das fontes da escola, mas não desconsideram a importância das relações externas a ela, ou seja, as forças políticas, econômicas, culturais e as disputas em torno dos objetivos destinados às diferentes disciplinas naquele momento específico da história brasileira.

\section{As fontes da escola e os arquivos escolares}

O debate acerca dos arquivos escolares tem se tornado mais freqüente a partir da década de 1990, no Brasil, aliado às questões colocadas pela História Cultural, cujo interesse e uso de referenciais têm sido crescentes, na História da Educação, como aponta Fonseca (2003).

As questões referentes à cultura escolar e a fontes que permitam sua percepção e estudo acabam por fazer voltar os olhares aos arquivos escolares, em busca de registros documentais que contribuam para a reconstituição da cultura material escolar das instituições educativas. A escola produz, em seu cotidiano, diversos tipos de documentos e registros, exigidos pela burocracia escolar. Há toda uma legislação que orienta essa produção, como exigência para a legalidade das ações da instituição, envolvendo seu 
funcionamento, e a organização e controle de suas atividades. Além disso, pode-se encontrar no arquivo da escola outros tipos de documentos que excedem a determinação legal, como fotografias, jornais produzidos pelos estudantes, cadernos de alunos, recortes de jornais com matérias referentes à instituição, bilhetes, entre outros.

Esses documentos comprobatórios do cotidiano da instituição escolar constituem registros que foram produzidos "por instituições ou indivíduos singulares, tendo em vista não uma utilização ulterior, e sim, na maioria das vezes, um objetivo imediato, espontâneo ou não, sem a consciência da historicidade, do caráter de 'fonte' que poderia[m] vir a assumir mais tarde." (ROUSSO, 1996, p.87).

Neste sentido, cabe lembrar uma concepção mais ampla de documento. Segundo Le Goff (2003, p. 537-8),

O documento não é inócuo. É, antes de mais nada, o resultado de uma montagem, consciente ou inconsciente, da história, da época, da sociedade que o produziram, mas também das épocas sucessivas durante as quais continuou a viver, talvez esquecido, durante as quais continuou a ser manipulado, ainda que pelo silêncio. $O$ documento é uma coisa que fica, que dura, e o testemunho, o ensinamento [...] que ele traz devem ser em primeiro lugar analisados, desmistificando-lhe o seu significado aparente. $\mathrm{O}$ documento é monumento. Resulta do esforço das sociedades históricas para impor ao futuro - voluntária ou involuntariamente determinada imagem de si próprias.

Tendo sido produzidos com maior ou menor consciência e intencionalidade - o que pode ocorrer, em alguma medida, com documentos oficiais, como atas ou relatórios, por exemplo -, tais documentos registram e constituem a cultura material escolar, específica daquela instituição, profundamente relacionada, de forma dialética, com a sociedade e a cultura mais ampla, em que está situada. Ou seja, são testemunhos da vida institucional, da sua cultura e memória, com as particularidades da escola que os produziu. Nesse sentido, se considerado para a compreensão da instituição, internamente a ela.

São vários os autores que têm se preocupado, na História da Educação, com a discussão sobre a relevância de estudos referentes aos arquivos escolares, e também sobre sua conservação, organização, e relevância das fontes neles encontradas para estudos da área. Por exemplo, Ragazzini (2001, p. 26) afirma:

[...] é de grande importância o desenvolvimento de uma consciência e de uma prática documentária de individualização, catalogação e conservação dos documentos. As novas identidades da História da Educação foram muito discutidas, assim como as possibilidades de uma aproximação inovadora com a história da escola, contudo, enquanto permanecemos sem uma prática de documentação adequada, permaneceremos no âmbito das discussões acadêmicas ou do pioneirismo. Uma historiografia mais sofisticada requer uma inovação no uso das fontes e isto não será possível sem uma nova prática de pesquisa, uma nova prática arquivista e uma nova sensibilidade documentária.

No caso da história das instituições educacionais, Magalhães destaca como o arquivo escolar é fonte essencial, uma vez que a trajetória da instituição é construída "da(s) memória(s) para o arquivo e do arquivo para a memória" (1998, p.61), buscando-se integrar uma análise multidimensional desse itinerário. Contrapondo-se à relevância e riqueza do material encontrado nos arquivos escolares, o autor também destaca sua 
preocupação com seu estado de guarda e conservação, indicando que a situação nas instituições educacionais de Portugal não é tão distinta daquela encontrada nas do Brasil:

[...] Sede privilegiada de uma multiplicidade de acções humanas, pedagógicas, culturais, sociais, afectivas, produto de um quotidiano sempre reinventado, da instituição educativa não resta por vezes mais que um resíduo documental, irregularmente repartido no tempo e pouco representativo, nomeadamente no que se refere à riqueza do quotidiano escolar (MAGALHÃES, 1999, p.75).

Por sua vez, Vidal (2005), com base nas observações de Nora (1993), destaca os arquivos como lugares de memória, lugares duplos enquanto locais de guarda de seus acervos, mas ao mesmo tempo, "constantemente abertos a novas leituras acerca do passado e o presente" (p.19).

Estes lugares necessitam de tratamento adequado, com organização e descarte entendidos como procedimentos complementares, situados dentro de um processo técnico, no campo da arquivística, que exige, dessa forma, o diálogo entre historiadores e arquivistas. Tratando-se da especificidade dos documentos e arquivos escolares, o esforço deve ocorrer no sentido de transformar o arquivo morto em arquivo histórico, ou seja, organizado, catalogado, e funcionalmente integrado ao arquivo corrente, discutindo-se e criando-se, no âmbito da instituição educacional, critérios para conservação e descarte, planos de destinação da documentação, elaborados "para além da lógica administrativa" (VIDAL, 2005, p.22), de forma a abranger outros âmbitos que ultrapassem a Secretaria da escola e a norma legal.

\section{O arquivo histórico escolar do Colégio Estadual do Paraná: encaminhamentos e contribuições para a pesquisa em História da Educação}

Várias especificidades tornaram o Colégio Estadual do Paraná - CEP - um local privilegiado para a investigação sobre História da Educação, o que o torna presente - seja como objeto de pesquisa, seja como sede de acervo utilizado para investigações - em vários trabalhos acadêmicos. Pode-se destacar, destas características, a sua trajetória histórica, desde a criação da instituição como Licêo de Coritiba, em 1846; a busca, registrada e reiterada, de ser referenciado e comparado ao Colégio Pedro II; a atual sede ser patrimônio histórico tombado; os recursos privilegiados para uma escola pública, inclusive um espaço físico que permitiu a guarda e preservação de significativo acervo documental.

Em contraste com a realidade da maioria das escolas, o estado de conservação dos arquivos do CEP é razoável, e permite o manuseio dos documentos. Isso se deve a várias razões, inclusive relacionadas às suas especificidades históricas. Porém, não havia uma organização e inventário desse acervo, o que dificultava e limitava o acesso e a localização de fontes, e mesmo a indicação de quais existiam na instituição.

Em 2006 teve início um projeto de organização deste acervo documental ${ }^{1}$, visando, em especial, a constituição de um banco de dados. Considerando que transformar o arquivo "morto" em arquivo histórico implica em organizá-lo, os procedimentos foram os sugeridos por Vidal e Zaia (2001), a partir da experiência desenvolvida em arquivos escolares de escolas técnicas do Estado de São Paulo. Os seguintes passos estão sendo seguidos no projeto: diagnóstico da documentação; registro fotográfico do local em que se encontra a documentação, antes, durante e depois do trabalho de organização; levantamento e agrupamento do material; higienização; estabelecimento de critérios de 
avaliação, amostragem e descarte; escolha do local para guarda da documentação; acondicionamento da documentação; organização e notação dos documentos.

No CEP, foi realizado o levantamento e organização cronológica dos documentos, até 1980 - data estabelecida como limite provisório entre o arquivo histórico e os arquivos corrente e intermediário; a organização dos documentos por período histórico do CEP: 1846 (criação) a 1876 - Licêo de Coritiba - LC; 1876 a 1892 - Instituto Paranaense - IP; 1892 a 1942 - Gymnásio Paranaense - GP; 1942 a 1943 - Colégio Paranaense - Externato - CP; 1943 a 1980 - Colégio Estadual do Paraná - CEP; o estabelecimento de séries, que se referem aos locais de produção dos documentos, por exemplo, Biblioteca, Coordenação Pedagógica, Direção; a definição de sub-séries, relativas aos tipos de documentos encontrados como atas de concursos, material didáticos, ofícios enviados, laudos de inspeção, atas de exames finais; a instalação e adequação de um software para o banco de dados - no caso, foi utilizado o WinIsis, da UNESCO; e, a fase atual, composição do banco de dados, no qual cada documento tem as seguintes informações: número (referente ao acervo), série, sub-série, autor, data, número de páginas, suporte, formato, fundo, responsável pelo registro, conteúdo e palavras-chave.

As séries, que correspondem às unidades internas de origem dos documentos, podem variar conforme o período, devido à organização administrativa da instituição. Foram identificadas as seguintes séries: APM - Associação de Pais e Mestres; B Biblioteca; CP - Coordenação Pedagógica; D - Direção Geral; DF - Departamento Financeiro; OE - Orientação Educacional; RH - Recursos Humanos; e SA - Secretaria Acadêmica.

Por sua vez, as sub-séries correspondem aos tipos de documento. Foram identificadas mais de oitenta sub-séries, como atas de concursos, exames, materiais didáticos e ofícios.

No banco de dados todos os documentos já organizados - cerca de 900 itens, entre avulsos e conjuntos encadernados - estão catalogados, com as informações de notação acima mencionadas. Encontra-se em andamento a descrição pormenorizada de cada documento, que contempla, por exemplo, temas debatidos nas reuniões registradas em um livro de atas. Um exemplo da ficha preenchida para cada documento encontra-se na Figura 1.

Figura 1 - Modelo de ficha do banco de dados - acervo histórico escolar do CEP 


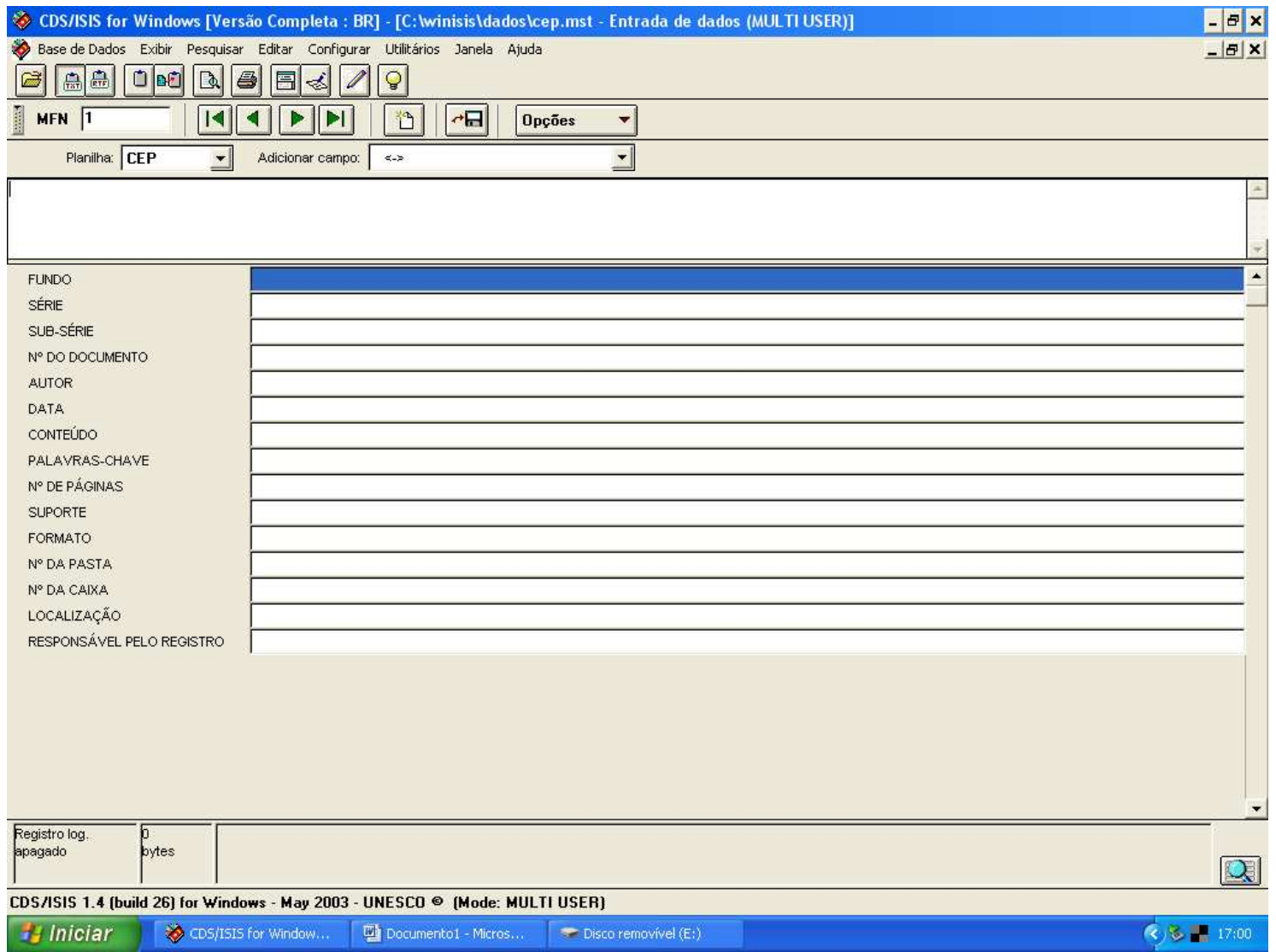

Esta ficha permite diferentes possibilidades de busca por parte dos pesquisadores, uma vez que cada campo pode servir de orientador da busca, podendo-se optar ainda por campos combinados. O programa, simultaneamente ao preenchimento das fichas, gera automaticamente uma lista de palavras-chave cadastradas.

Para o desenvolvimento de todos estes procedimentos, ressalta-se colaboração de bolsistas e voluntários ${ }^{2}$ no desenvolvimento direto do trabalho. Os colaboradores, antes de manusearem a documentação, foram orientados quanto à higienização e preservação documental, bem como sobre cuidados de proteção necessários, seja por meio de bibliografia, seja com um treinamento básico realizado no Arquivo Público do Estado do Paraná.

A questão dos recursos humanos para a organização de qualquer acervo documental é um desafio a ser enfrentado, em especial na parte inicial das atividades, em que há uma grande quantidade de documentos que precisam ser avaliados, higienizados, organizados e acondicionados. Estes procedimentos, embora requeiram orientação técnica, não são muito complexos, mas são muito braçais, lentos, sendo que os progressos demoram algum tempo para poderem ser observados.

Também, em relação aos recursos materiais, algumas etapas foram vencidas e alguns desafios precisaram ser enfrentados. Inicialmente, a questão do espaço para a higienização e organização dos documentos, uma vez que a sala onde estavam depositados, além de abarrotada, tinha muita poeira acumulada, não fazendo sentido processar os documentos e guardá-los em armários de madeira, nem junto ou próximo de outros ainda a serem limpos. Neste projeto, a Direção Geral do CEP cedeu uma sala em outro local, para onde foram levados os documentos (o primeiro conjunto, até 1980), e que já se encontra lotada, sendo solicitada outra sala para a continuidade destas atividades. 
Outro desafio é a aquisição de equipamentos, do mobiliário e do material para acondicionamento dos documentos organizados e para proteção dos envolvidos. Neste projeto, foram adquiridos alguns equipamentos, como esterilizador de ar e computador, bem como luvas, máscaras, óculos de proteção, guarda-pós, entre outros, com recursos complementares, da Fundação Araucária, da Secretaria da Educação e do CEP.

Compreende-se que esta situação ocorre cotidianamente em uma instituição privilegiada como o CEP, em outras instituições escolares eles são potencializados, em relação a espaço, recursos humanos e materiais. Neste caso, alguns desdobramentos foram originados deste projeto, em dois níveis principais: administrativos e arquivísticos. Os arquivísticos foram brevemente relatados acima. No caso dos administrativos, trata-se da maneira como se deu o contato com a Direção Geral do CEP e os funcionários responsáveis pela guarda do acervo e do Museu Guido Straube, o que será abordado em seguida.

\subsection{Ações institucionais e parcerias externas ao CEP}

Primeiramente, deve-se ressaltar que a proposta feita ao CEP foi muito bem recebida, dada a falta de funcionários para organizar o acervo e atender aos pesquisadores que demandavam por consultas aos documentos.

Já no contato inicial com a Direção Geral do CEP, propôs-se a formação de uma Comissão Gestora do projeto junto à instituição escolar, com o intuito de discutir coletivamente as questões referentes à infra-estrutura física e humana necessária para seu desenvolvimento, bem como outras questões administrativas, como avaliação e descarte de documentos e procedimentos e orientações internas aos funcionários. A Comissão foi composta por representantes da Universidade Federal do Paraná - UFPR; da Direção Geral, arquivo geral e Museu do CEP; da comunidade do CEP; e da Secretaria de Estado da Educação - SEED, e tem funcionado desde o preparo para a realização das atividades, em agosto de 2006. Recentemente, foi incorporada à Comissão uma representante do Arquivo Público do Estado do Paraná.

Ainda em 2006, o projeto tomou um porte mais amplo e institucional. Diante do acervo encontrado houve um desdobramento: guardados junto dos documentos estavam objetos diversos, uma precária reserva técnica do Museu existente na instituição, mas muitos em péssima situação de conservação, como filmes pedagógicos da década de 1950. Após discussões da Comissão o resultado foi um desdobramento do projeto: a proposição de criação do Centro de Memória do CEP em um espaço único, articulando o Museu Guido Straube (a ser reorganizado e ressignificado), a Seção de Documentação Histórica e a Seção de Proteção de Patrimônio Histórico (ambas criadas pela Comissão nesse momento). Dessa forma, embora o projeto originário da pesquisa permaneça com seu foco na organização e inventário do acervo documental, este já produziu um efeito institucional muito positivo.

Uma das conquistas a partir dessa proposição, que foi apresentada e aprovada pela Direção Geral do CEP, foi a cessão de um espaço mais amplo, para a instalação do Centro de Memória. Este espaço era a antiga casa do zelador, atualmente em reforma.

O Centro de Memória tem exigido ações internas ao CEP, tanto no sentido de conseguir um espaço e condições adequadas para sua instalação, quanto no de sensibilizar a comunidade escolar sobre sua relevância, a fim de obter colaboração. Por exemplo, já foi realizada reunião com todas as chefias e direções para esclarecimento sobre o projeto e orientações iniciais sobre cuidados com os documentos que geram, desde guarda à triagem 
e procedimentos de descarte; da mesma forma, alterações no regimento interno e no regimento escolar estão encaminhadas; além da previsão para que ocorra a formação de uma Comissão para avaliação da destinação dos documentos.

Outro desafio interno remete aos conhecimentos necessários para a reorganização do Museu Guido Straube, que envolve desde a realização do inventário do acervo, ao desenvolvimento do plano de gestão museal, do projeto para aquisição de equipamentos e mobiliários, entre outros.

Como encaminhamentos externos, algumas demandas têm sido postas à Secretaria da Educação do Estado do Paraná, no sentido de subsidiar e incentivar a proposição de uma política pública relativa à preservação de acervos históricos escolares. Neste sentido, destacam-se:

- a solicitação de elaboração de manuais de orientação para as escolas, relativos a documentos (cuidados, preservação, critérios e procedimentos de descarte, amostragem, tabela de temporalidade específica para a documentação gerada por uma instituição escolar), a objetos e à arquitetura escolares. Em relação a essa demanda os representantes da SEED na Comissão, estão construindo uma parceria com o Arquivo Público do Paraná; e - a solicitação de oportunidades de formação continuada, para direção e secretários das escolas, em especial, mas aberto a demais interessados, relativos ao tema e aos referidos manuais. Também promovido pelos representantes da SEED, em agosto terá início a primeira oferta do Curso "Princípios e Práticas da Gestão do Patrimônio Histórico Escolar", que, pretende-se, deverá ser expandida para vários núcleos regionais do Paraná.

A partir do conjunto dessas iniciativas, diretamente relacionadas ao acervo documental do CEP e em busca de recursos humanos e materiais para o desenvolvimento das atividades e desdobramentos institucionais já relatados, compreende-se que houve avanços significativos em relação ao proposto inicialmente, e ao apoio recebido, interno e externo ao CEP. Na fase atual de desenvolvimento do projeto, todos os documentos foram avaliados, higienizados e organizados e possuem a ficha do banco de dados parcialmente preenchida, com a descrição dos dois últimos itens, conteúdo e palavra-chave, em andamento. Porém, a partir das informações disponibilizadas no banco de dados, já é possível identificar e localizar mais facilmente os documentos existentes, muito diversificados quantitativa, qualitativa e tipologicamente.

Como exemplo do potencial do Arquivo Histórico do CEP como lugar de guarda e preservação de fontes relevantes para pesquisas em História da Educação, destacam-se registros que podem contribuir mais diretamente para investigações relativas a disciplinas escolares, como: livros de ocorrência, planos de ensino; conteúdos programáticos; material didático; horários de aula; projetos para disciplinas; quadro de professores; diários de classe; atas de reuniões de professores e pais; planos e projetos pedagógicos; currículos; regimento interno; jornais acadêmicos; relatórios diversos; e quadros demonstrativos do número de professores, aulas, alunos e turmas. No tópico seguinte, este exemplo será discutido, a partir de duas dissertações e uma tese sobre este tema, defendidas na Linha de História e Historiografia da Educação do PPGE-UFPR.

\section{As fontes da escola e o campo das disciplinas escolares no ensino secundário: uma reflexão sobre o seu alcance}

A chamada escola secundária ou ensino secundário tem merecido a atenção de estudiosos em países do mundo ocidental numa ordem crescente de investimentos, principalmente no âmbito da história do currículo. Nesse sentido, o estudo histórico de 
disciplinas escolares tem sido uma referência para um olhar que observa e analisa o processo de constituição desse tipo de escolarização, das escolhas curriculares em determinados momentos e dos interesses que possibilitam a manutenção ou mudanças das disciplinas ou de parte delas. Além disso, uma análise que leva em consideração "as formas assumidas por uma disciplina, desde a sua emergência e no curso de sua evolução, possibilita compreender os fatores que atuam na definição da prática curricular"(SANTOS, 1995, p. 61).

A literatura sobre a história das disciplinas escolares (CUBAN, op cit, SANTOS, 1992, p. 224; SANTOS, 1995; CHERVEL, 1990; BITTENCOURT, 2003; e TABORDA e RANZI, 2003) aponta fatores internos ligados à escola e fatores externos ligados ao contexto social como motivadores de mudanças no âmbito escolar. Destacam-se as questões relacionadas com o poder, controle, coalizões, negociações e compromissos entre grupos e indivíduos, operando dentro e fora do sistema escolar. Outras influências são motivadas por editoras de livros didáticos, fundações ou instituições de amparo à pesquisa, associações profissionais e indivíduos de liderança intelectual na área. Os mesmos fatores que promovem as mudanças podem contribuir para a estabilidade do currículo escolar. Segundo Santos, respaldada por Kleibard, a questão é complexa, pois diferentes idéias disputam prestígio e aceitação no campo do currículo, mas não conseguem sozinhas se impor. Os eventos sociais e políticos não definem por eles mesmos a direção do currículo. Ou seja, eventos sociais e políticos tornam plausíveis ou implausíveis certas idéias existentes (SANTOS, 1995, p. 62).

Algumas questões irão nortear a reflexão que pretendemos fazer com as três pesquisas realizadas no CEP sobre a História das disciplinas escolares - Educação Física (CHAVES JR., 2004), Canto Orfeônico (LEMOS JR., 2005) e História (KAWKA MARTINS, 2006). Foi possível captar e analisar o que fazia parte do currículo e o que facilitava ou não a mudança no âmbito da escola? O que pode ser comparado? Por que há uma predisposição em afirmar que as disciplinas escolares não mudam? Uma disciplina ou matéria com a mesma denominação sofre, no tempo, que tipo de mudança? Houve variação na forma e no conteúdo?

Ressalta-se a preocupação dos autores em direcionar um olhar mais atento à internalidade do trabalho escolar com o objetivo de entender a constituição das disciplinas escolares, de acompanhar as mudanças no tempo, e identificar como atuaram os fatores internos e externos à escola na definição da prática curricular. As três produções analisadas têm um recorte e uma problematização regional, mas estão sintonizadas com o movimento internacional de ampliação dos objetos de estudo principalmente pela incorporação de fontes antes pouco exploradas localmente. Os três autores trabalham a relação entre as reformas educacionais para o ensino secundário no Governo Getulista e os objetivos pedagógicos do governo em dar destaque primordial à juventude.

Nos chamados Tempos de Capanema (1934-1945),

[...] ao Estado caberia a responsabilidade de tutelar a juventude, modelando o seu pensamento, ajustando-o ao novo ambiente político, preparando-a, enfim, para a convivência a ser estimulada no Estado totalitário. [...] Era indispensável que houvesse símbolos a serem difundidos e cultuados, mitos a serem exaltados e proclamados, rituais a serem cumpridos" (SCHAWRTZMAN; BOMENY E COSTA, 2000, p. 83).

Nesse sentido o estudo centrado nas disciplinas escolares permitiu verificar de que forma elas estariam contribuindo ou não para a consolidação de um determinado 
nacionalismo. Outro objetivo dos autores foi entender o processo de consolidação ou não das três disciplinas estudadas centrando a análise na metodologia utilizada e nos conteúdos exigidos e praticados.

Finalmente, dois esclarecimentos são necessários: a instituição estudada, no período de 1931 a 1950 sofreu mudança na sua denominação, conforme já indicado, passou de Ginásio Paranaense para Colégio Paranaense (1942) e para Colégio Estadual do Paraná (CEP) (1943), seu nome atual. Como os autores analisados trabalharam este período de transição o nome do colégio pode aparecer nas três variações; e o nome do jornal dos estudantes também foi mudando, acompanhando as mudanças da instituição escolar. São suas denominações no período: Jornal Ginásio Paranaense Externato, Jornal Colégio Paranaense e Jornal Colégio Estadual do Paraná e por alguns anos foi editado também o Jornal Guairacá, da seção feminina do Ginásio Paranaense.

\subsection{Qual o alcance dos relatórios de inspetores como fonte pra compreender o que se faz ou e o que não se faz na escola?}

A partir da análise dos relatórios sobre o funcionamento da disciplina de Educação Física, Chaves Jr. sugere uma prática no Ginásio Paranaense que segue orientações e exames médicos numa ênfase biológica de separação, padronização, normalidade e anormalidade dos alunos para definição de atividades ligadas à educação física (2004, p. 53). A disciplina de Educação Física a partir de 1930, foi alvo de investimentos perceptíveis nos conteúdos legislativos, e nos discursos de diversas autoridades, como governantes, inspetores, diretores e professores. Para o autor, a obrigatoriedade da disciplina, estendida para todos os níveis de ensino, foi a maior realização deste período levando em consideração o seu papel como coadjuvante no processo de desenvolvimento da nação, fortalecendo os corpos e ajudando a formar mentes.

Nesse sentido, Chaves Jr. identifica uma singularidade local sobre a forma como a disciplina vai contribuir, no Paraná, para servir aos interesses exteriores à escola, mesmo com as dificuldades para cumprir a legislação - estender a oferta da referida disciplina escolar para todos os alunos. Neste período estudado houve um esforço do Ginásio em atender pelo menos o público masculino. A forma que o autor encontrou para saber se os conteúdos definidos pela legislação eram cumpridos foi cruzar as informações escritas com a fonte oral, o que possibilitou inferir que não era possível a execução de todo o programa. O ginásio não tinha a infra-estrutura necessária para atender a toda demanda curricular, o que o levou a direcionar o ensino da Educação Física para o esporte. Ao mesmo tempo foi um período em que foram dadas as condições para um processo de valorização crescente da disciplina no GP tendo como o ápice a inauguração das instalações esportivas do novo prédio no início da década de 1950.

Para a disciplina de Canto Orfeônico, Lemos Jr. (2005) argumenta que mesmo a simpatia do ministro Francisco Campos pela música e a defesa que fez do seu ensino não garantiram uma carga horária equivalente a outras disciplinas. Para o autor, a carga horária 5 horas/semanais nas três primeiras séries do curso ginasial era tímida, com o agravante que essa carga horária definida nacionalmente não precisava ser cumprida, pois como ele comprovou, no Paraná as aulas semanais eram em menor número. Lemos Jr. foi buscar nas avaliações da disciplina escolar, que tiveram a sua obrigatoriedade prevista somente em 1946, os dados que permitiram verificar se determinados conteúdos eram aplicados de fato na escola. Os alunos eram avaliados nas dimensões teórica e prática da disciplina. 
Pela análise das avaliações, o autor percebeu que havia um esforço em cumprir o mínimo exigido nos programas oficiais.

No Paraná os professores não tinham formação específica de professor de música, mas figuravam entre aqueles que conheciam e defendiam a música erudita e nesse sentido ele se diferenciava de outros estados, pois não havia queixa de desinteresse dos alunos em cursar a disciplina.

A finalidade do Canto Orfeônico na escola, no entanto, nem sempre priorizava o desenvolvimento da sensibilidade musical e estética dos alunos. Essa disciplina era vista também com a finalidade de disciplinar e socializar os alunos e contribuir para a educação moderna, Lemos Jr. detectou que no cotidiano da escola a disciplina de música desempenhava mais esse papel, pois tinha a atribuição de melhorar a respiração, a circulação sanguínea e de promover recreação, portanto tinha também um apelo higienista. Outro aspecto importante é a questão racial, o canto deveria contribuir para a homogeneização cultural, que era buscada na raiz tipicamente brasileira na arte, na música (LEMOS JR., 2005, p.51-52).

Para a disciplina escolar de História havia uma expectativa positiva de Kawka Martins (2006) com relação aos relatórios dos inspetores entre as décadas de 1930 e 1940. No entanto, o que ela observou foi que os relatos se repetiam e eram, muitas vezes, cópias das orientações metodológicas da orientação legal, como se aquilo que estava proposto fosse totalmente aplicado. Os relatórios não contribuíram para analisar a visão dos inspetores sobre o currículo praticado, pois sugeriam uma análise burocrática apenas e não indicavam problemas, acertos ou deficiências, que seria o esperado.

Os inspetores relatavam como se tivessem assistido a muitas aulas dos professores e pretendiam demonstrar como estes estariam seguindo à risca as recomendações metodológicas, ou seja, nas primeiras séries do secundário, os professores trabalhavam um caráter mais episódico e biográfico da História e, nas séries seguintes, um maior aprofundamento intelectual que exigia mais dos alunos. A questão do trabalho com as imagens também era uma recomendação que os professores seguiam e que dava ótimos resultados, segundo os inspetores.

A argumentação se repetia em vários relatórios e anos diferenciados. $\mathrm{O}$ inspetor deixava de ser tão maleável na análise da atuação do professores e ficava menos burocrático e na defensiva quando tinha que fazer uma análise das repetências. O número de repetências acaba sendo atribuído, em grande parte, ao professor que não conseguia entender as diferenças entre os alunos, que não sabia dialogar e ouvir os alunos. A extensão dos programas e a falta de hierarquização dos conteúdos teria sido mais um dos motivos elencados pelos inspetores (KAWKA MARTINS, 2006, p. 92-3).

Outra fonte utilizada pela autora e cotejada com os programas oficiais foi o programa da disciplina de História, que divergia dos relatórios dos inspetores e permitiu a constatação de que a escola não seguia à risca o indicado e proposto e, muitas vezes, o professor trabalhava uma quantidade bem menor de conteúdos. Essa realidade não foi uma singularidade do colégio Estadual do Paraná; em nível nacional alguns estudos dos inspetores incluíam reclamações dos professores sobre o excesso de conteúdos exigidos para o ensino de História e o número de horas/aulas destinadas para cumprir as determinações. Dessa forma, os relatórios dos inspetores, programas do Ginásio e o programa oficial dão uma mostra de que o professor na sua prática escolhia determinados conteúdos em detrimentos de outros. Esta iniciativa exigiu mudanças nas provas parciais e totais e uma crítica às observações curriculares que exigiam um conteúdo enciclopédico e ao mesmo tempo cobrava do professor menos preleção, mais participação do aluno e um 
trabalho com outros materiais que o aluno pudesse interagir ativamente (KAWKA MARTINS, 2006, p. 87-88).

O colégio dispunha de uma sala própria para o ensino de História, o que já a diferenciava do problema encontrado nas outras duas disciplinas - Educação Física e Canto Orfeônico-, que não possuíam um espaço adequado. A sala ambiente de História contava com mapas históricos, quadros murais sobre História do Brasil. A disposição das carteiras e outros indícios relatados por críticos da época motivaram a autora a questionar se houve mesmo uma participação mais ativa do aluno - como pregava o programa - e se o professor fazia o mínimo de preleção, como afirmavam os inspetores em seus relatórios.

Para a disciplina de História, além das provas parciais serem avaliadas pelo professor, eram supervisionadas pelo inspetor e depois lacradas e guardadas no estabelecimento. As provas orais eram compostas por três professores e o inspetor presidia a avaliação. Uma prova feita sem a presença e o aval do inspetor era anulada. Foi constatado que na prática do professor o número excessivo de provas parciais e o tempo destinado à argüição dos alunos na prova final exigia um tempo muito grande do horário de um ano letivo. O Inspetor do Ginásio fez um cálculo do tempo desperdiçado em provas para cumprir todas as exigências e afirma que necessitaria de mais de 100 dias letivos para cumpri-las e admitia ainda ser quase impraticável participar de todas as provas do secundário.

Esses dados sobre as provas foram encontrados no relatório do inspetor que queria parecer muito cuidadoso e eficiente, no entanto, o jornal dos estudantes ridicularizava o excesso de rigor da inspetoria, mostrando como os professores permitiam e incentivam a cola e como esse processo se deu cada vez mais sistematicamente entre os alunos, nas provas escritas e nas provas orais. Nesta última, era denunciado pelo jornal que a argüição era feita em meia voz para que ninguém pudesse ouvir a questão e a resposta. Enfim, o processo de resistência e as práticas gazeteiras às normas foram sendo aperfeiçoados e o pretenso rigor da avaliação, ridicularizado no Estado do Paraná, principalmente pelos estabelecimentos privados (KAWKA MARTINS, 2006, p. 123).

\subsection{O Jornal dos Estudantes: uma fonte para analisar a disciplina escolar para além da sala de aula}

O jornal dos estudantes foi uma fonte que possibilitou a análise da participação das três disciplinas na efetivação da proposta dos ideólogos do governo ditatorial e da propaganda Getulista na arregimentação da juventude em defesa de um ufanismo proposto e construído neste período com o apoio da escola.

$\mathrm{Na}$ disciplina de História, a imprensa escolar e os demais periódicos foram utilizados para averiguar a contribuição dessa disciplina na construção de uma memória histórica e de uma cultura cívica nos espaços fora da sala de aula. Kawka Martins (2006) discute a questão da construção de uma memória histórica e mostra como em momentos de crise e de tensão aumenta a preocupação institucional com a questão da memória e da identidade. Nesse sentido, as fontes da escola permitiram-lhe acompanhar o processo de imposição na comemoração de determinadas datas criadas pelo Governo de Getúlio e de demonstrar como a instituição escolar contribuiu para essa exaltação nos dias "da raça", "aniversário do presidente Getúlio" e no dia de "comemoração da instalação do Estado Novo". Essas datas vão ser apropriadas de algumas comemorações já existentes e mantidas, como o dia da Bandeira e o dia da Pátria. A forma de comemoração também variava; por exemplo, o dia da raça e o dia Pátria eram celebrados externamente, diante de 
toda a comunidade, e outras como o dia do professor e o dia da República, no interior da escola. A participação dos estudantes era muito significativa e elogiada pela imprensa local. A fonte serviu para analisar como os estudantes se manifestavam sobre acontecimentos da época - com referência ao governo e ao personagem Getúlio Vargas, à Segunda Guerra Mundial e às comemorações. E ainda, perceber e analisar os temas e a concepção de História que predominava nos editores do periódico escolar quando tratavam de questões históricas.

Para a disciplina de Canto Orfeônico, Lemos Jr. (2005), que também analisou a participação dessa disciplina nas festas escolares, tal qual a de História, identificou que após a intervenção de Villa-Lobos no quadro educacional brasileiro, as festas escolares com a participação dos orfeões se espalharam pelo país. No Paraná, os estudantes secundaristas promoviam festas nas datas comemorativas nacionais e em homenagem a vultos específicos. Os eventos incentivados por Villa-Lobos e pelos ministros da Educação do período - Francisco Campos e o Ministro Capanema - ganharam espaço na escola e foram, sistematicamente, reforçados pela imposição governamental como um importante instrumento de celebração de determinados acontecimentos tidos como formadores de uma dada nacionalidade, na perspectiva de promover a socialização da juventude e, ao mesmo tempo, fortalecer o governo ditatorial de Getúlio Vargas. Além desses aspectos, ficou claro para o autor que havia nas celebrações uma intencionalidade em divulgar a música erudita considerada de qualidade, sem deixar de contemplar os artistas populares preocupados com a tradição cultural das canções folclóricas, logicamente com um aprimoramento técnico de composição e interpretação.

Para a disciplina de Educação Física, Chaves Jr. (2004) localizou nos jornais estudantis, a partir de 1940, uma seção especial denominada Olímpia que tratava das questões da Educação Física. Nela, os estudantes divulgavam o resultado de jogos colegiais, opiniões sobre assuntos esportivos diversos e era também um canal de exaltação e chamada para as aulas e treinamento esportivos. Ele conclui que este periódico estudantil contribuiu para a valorização da disciplina e também para uma mudança de paradigma, pois a partir dos resultados alcançados com a prática esportiva e a divulgação pelos estudantes houve um reforço rumo à esportivização da disciplina nos anos 50. Percebe, ainda, uma participação ufanista dos alunos que editavam o periódico estudantil, ao defenderem o esporte para o desenvolvimento da força e da moral contribuindo para reforçar os ideais de construção da nação proposta pelo governo de Getúlio Vargas. Algumas críticas sobre a falta de infra-estrutura e de materiais para o esporte também fizeram parte do jornal, a partir de 1948, quando esse jornal já circulava sem a censura da ditadura.

\subsection{O que muda na escola com o fim da ditadura do Estado Novo?}

Para a Educação Física os programas, os conteúdos e a tentativa dos professores e da escola para atingir os objetivos da disciplina levaram a definição de prioridades e a mudança de enfoque. Chaves Jr. (2004) observou que ela saiu da ginástica para uma "esportivização" que vai acontecer no final do período estudado e recortado por ele (1951), que coincide, com o que chama de o ápice da valorização e da consolidação da disciplina escolar no Ginásio Paranaense. Alguns fatores contribuíram para essa afirmação: mudança para o novo prédio com amplos espaços e materiais, e contratação de professores com formação específica. 
A análise de Lemes Jr. (2005) em relação ao Canto Orfeônico é de que a mudança de regime político não arrefeceu o investimento nesse ensino, ao contrário ele prosperou. Houve ainda uma década de incentivo e o número de apresentações festivas prosseguiu. No entanto apresentação do canto orfeônico não tinha mais uma programação ufanista e nem ocorria somente em datas cívicas, mas principalmente em eventos internos da própria escola.

O que muda com o fim da ditadura para a disciplina de História? Muda o enfoque dos conteúdos de História do Brasil. Entram conteúdos que se contrapõem ao período anterior questionando e criticando o Estado Novo e o processo antidemocrático do período Getulista. Kawka Martins (2006) observou também a mudança na estrutura do jornal dos estudantes no período pós-Getúlio: a redação ficou menos formal, os assuntos mais leves e tornou-se perceptível o fim do caráter ufanista e patriótico que predominou no período anterior a 1946.

\section{Considerações Finais}

Fazer esse esforço de análise é importante, pois pode evidenciar a diversidade de documentos de acervos escolares para a produção de pesquisas no campo da História da Educação; a contribuição significativa que a organização desses acervos e sua disponibilização e divulgação podem gerar para a produção de novas pesquisas; e, a partir de investigações já concluídas, pode contribuir para abordagens comparativas de elementos que possam ser comparados e mostrar aquilo que é comum na compreensão e implantação de políticas públicas de educação, e aquilo que é singular em função de soluções e/ou problemas específicos no "local".

Entende-se que a iniciativa em desenvolvimento no CEP pode ser início para a sensibilização de outras instituições escolares e do Estado, para que haja condições físicas e humanas para a preservação dos acervos escolares, seja na escola de origem, ou em um projeto mais amplo, que abarque acervos de instituições que não têm condições de garantir sua preservação, bem como por meio de legislação específica, que contemple critérios claros de guarda e descarte da documentação escolar, ou ainda atribuindo responsabilidades sobre sua preservação. Considera-se que já são importantes os resultados alcançados com as iniciativas em andamento, internamente ao CEP, e como esboço de política pública da SEED.

Espera-se que, compartilhando e divulgando os caminhos percorridos no desenvolvimento do projeto, esses possam ilustrar possibilidades para novos projetos, problematizar e discutir as respostas até então encontradas e propostas, bem como a sua relevância para a própria instituição sede do projeto e para o campo da História da Educação.

Em relação às três pesquisas aqui analisadas, entende-se, em concordância com Ragazzini (2001, p.20-22), que as fontes escolares não são suficientes para se fazer uma história integral da escola e nem mesmo para esgotar um recorte temático sobre a prática escolar. Porém, o acesso à documentação do Ginásio Paranaense/Colégio Estadual do Paraná permitiu um olhar diferenciado sobre o passado escolar, em função do tipo e consistência da fonte, e em função da escolha temática e dos problemas pesquisados.

O caminho percorrido pelos autores aqui analisados - Chaves Jr. (2004), Lemos Jr. (2005) e Kawka Martins (2006) - foi de seguir a orientação de Nóvoa (1996) sobre um olhar mais atento à internalidade do trabalho escolar. Eles examinaram o Ginásio Paranaense como um lugar privilegiado na produção das disciplinas escolares mostrando o quanto ele foi dependente de interferências externas, principalmente no processo de reprodução ideológica, mas, por outro lado, não impediu que o êxito na manutenção e 
fortalecimento de algumas disciplinas acontecesse pelo desempenho e capacidade daqueles que acreditavam em seu potencial e em suas finalidades. Nesse sentido, as fontes foram fundamentais para a compreensão de alguns aspectos sobre as disciplinas escolares investigadas, como: a inexeqüibilidade dos programas pela extensão dos mesmos e pelo número de horas/aula; a falta de estrutura física; o empenho e desempenho dos professores; o papel do inspetor escolar no processo de controle das disciplinas e de suas atividades extra-classe exemplificadas nas atividades comemorativas.

E por fim, demonstraram como a fonte da imprensa escolar possibilitou a análise do uso da propaganda no período Getulista por meio dos alunos, através de um controle rigoroso daquilo que era veiculado, visando principalmente à defesa de um dado nacionalismo, e o enaltecimento do Estado Novo e de Getúlio Vargas.

Esses trabalhos, focados na História das Disciplinas, foram importantes para a História Institucional do Ginásio, e contribuíram, juntamente com outras pesquisas de períodos diferenciados para a compreensão dos processos e práticas que envolveram essa instituição escolar.

\section{Referências}

BASTOS, M H., BENCOSTA, M. L., CUNHA, M. T . Uma Cartografia da Pesquisa em História da Educação na Região Sul: Paraná, Santa Catarina, Rio Grande do Sul (19802001). Pelotas: Seiva, 2004.

BITTENCOURT, C. Disciplinas escolares: História e Pesquisa, In: TABORDA DE OLIVEIRA, M., RANZI, S. (Org.). História das disciplinas escolares no Brasil: contribuições para o debate. Bragança Paulista: EDUSF, 2003, p. 9-30.

CHAVES JR., S. J. A Educação Física do Ginásio Paranaense ao Colégio Estadual do Paraná: contribuições para a construção de uma história de uma disciplina escolar (19311951). Curitiba, 2004. Dissertação (Mestrado em Educação) - Setor de Educação, Universidade Federal do Paraná.

CHERVEL, A., História das Disciplinas Escolares: reflexões sobre um campo de pesquisa. Revista Teoria \& Educação, Porto Alegre, n.2, p.177-229, 1990.

FONSECA, T. N. L. História da Educação e História Cultural. In: VEIGA, Cynthia G. e FONSECA, Thaís N. L. (Orgs.). História e Historiografia da Educação no Brasil. Belo Horizonte: Autêntica, 2003, p.49-76.

KAWKA MARTINS, C. A disciplina escolar de História no ensino secundário público paranaense: 1931 a 1951. Curitiba, 2006. Tese (Doutorado em Educação) - Setor de Educação, Universidade Federal do Paraná.

LE GOFF, J. Documento/monumento. In: História e Memória. 5 ed. Campinas, SP: Editora da Unicamp, 2003, p. 525-541.

LEMOS JR., W. Canto orfeônico: uma investigação acerca do ensino de música na escola secundária pública de Curitiba (1931-1956). Curitiba, 2005. Dissertação (Mestrado em Educação) - Setor de Educação, Universidade Federal do Paraná.

MAGALHÃES, J. Um apontamento metodológico sobre a história das instituições educativas. In: SOUSA, Cynthia P. e CATANI, Denice B. (Orgs.). Práticas educativas, culturas escolares, profissão docente. São Paulo: Escrituras, 1998, p.51-69. 
Contributo para a História das Instituições Educativas - entre a memória e o arquivo. In: FERNANDES, Rogério e MAGALHÃES, Justino (Orgs.). Para a História do Ensino Liceal em Portugal: Actas dos Colóquios do I Centenário da Reforma de Jaime Moniz (1894-1895). Braga, Portugal: Universidade do Minho, 1999, p.63-77.

NORA, P. Entre memória e história: a problemática dos lugares. Projeto História, São Paulo, vol.10, p.7-28, dez/1993.

NÓVOA, A. História da Educação: perspectivas atuais. [S.I; Sn], 1996.

RAGAZZINI, Dario. Para quem e o que testemunham as fontes da História da Educação? Educar em Revista, Curitiba, UFPR, nr.18, p.13-28, 2001.

ROUSSO, H. O arquivo ou o indício de uma falta. Estudos Históricos, Rio de Janeiro, vol.9, nr.17, p.85-91, 1996.

SANTOS, L.C.P. História das disciplinas escolares: outras perspectivas de análise. Educação \& Realidade, Porto Alegre: UFRGS, v. 20, n. 2 , 1995, p. 48-60.

SCHAWRTZMAN, S., BOMENY, H.B, COSTA, V.R. Tempos de Capanema. Rio de Janeiro: Paz e Terra, 2000.

TABORDA DE OLIVEIRA, M., RANZI, S. (Org.). História das disciplinas escolares no Brasil: contribuições para o debate. Bragança Paulista: EDSF, 2003.

VIDAL, D.G. Cultura e prática escolares: uma reflexão sobre documentos e arquivos escolares. In: SOUZA, Rosa F. e VALDEMARIN, Vera T. (Orgs.). A cultura escolar em debate: questões conceituais, metodológicas e desafios para a pesquisa. Campinas, SP: autores Associados, 2005. Apoio: Unesp/FCLAr, p.3-30.

e ZAIA, I.B. De arquivo morto a permanente: o arquivo escolar e a construção da cidadania. In: MORAES, Carmem S. V. e ALVES, Júlia F. (Orgs.). Contribuição à pesquisa do ensino técnico no Estado de São Paulo: inventário de fontes documentais. São Paulo: Centro Paula Souza, 2001(?), p.33-42.

\footnotetext{
${ }^{1}$ Projeto financiado parcialmente pela Fundação Araucária.

${ }^{2}$ André S. Carvalho (UFPR), Bruna E. C. Oliveira (CNPq), Emanuelle G. R. Cordeiro (CNPq), Heloísa U. Silva (CNPq), Jozilei M. Souza (CNPq); Mariana R. Zacharias (CEP); Amanda L. Freitas, Guilherme B. Martins e Maria Eduarda W. Oliveira (IC Jr.-FA); e Ana C. Melo e Roberta D. F. Lincoln (estagiárias do CEP).
}

Artigo recebido em: 15/09/2009

Aprovado para publicação em: 20/10/2009

Revista HISTEDBR On-line, Campinas, n.37, p. 29-44, mar.2010 - ISSN: 1676-2584 